УДК 628.3:551.48

\title{
A.К. СТРЕЛКОВ
}

доктор технических наук, профессор, заведующий кафедрой водоснабжения и водоотедения, директор ООО НПФ «ЭКОС»

Самарский государственный архитектурно-строительный университет

\section{М.А. ГРИДНЕВА \\ кандидат технических наук, доцент кафедры водоснабжения и водоотведения \\ Самарский государственный архитектурно-строительный университет}

\section{Е.Е. КОНДРИНА}

аспирант кафедры водоснабжения и водоотведения, инженер I категории ООО НПФ «ЭКОС»

Самарский государственный архитектурно-строитедьный университет

\section{В АИЯНИЕ УРБАНИЗАЦИИ ГОРОДА НА СИСТЕМЫ ВОДООТВЕДЕНИЯ И ОЧИСТКИ ПОВЕРХНОСТНОГО СТОКА (НА ПРИМЕРЕ Г.САМАРЫ)}

\author{
INFLUENCE OF URBANIZATION ON THE SYSTEMS OF WATER DISPOSAL AND SURFACE DISCHARGE PURIFICATON \\ (IN SAMARA)
}

Рассмотрена проблема влияния соотношения типов поверхности городов на расходы дождевых вод, нагрузку на канализационные сети. Представлены поверочные расчеты для различных коэффициентов покрова на примере выпуска «Бельский» Самарского склона г.о. Самара. Выявлено, что чем больще коэффицичет покрова $z_{\text {mid" }}$ тем больще расчетный расход. Существующая дождевая сеть не справляется с поступающим количеством стоков. Увеличение диаметра или прокладка параллельных трубопроводов не всегда возможна и целесообразна. Следует рассматривать озеленение улии-как вспомогательный способ снижения нагрузки на сети.

Ключевые слова: тип поверхности, расход дождевых вод, коэффициент покрова, подпор.

Согласно разделу 4 [1], удельный вес озелененных территорий раздичного назначения в пределах застройки городов (уровень озелененности территории застройки) должен быть не менее 40 \%, а в границах территории жилого района - не менее 25 \% (включая суммарную площадь озелененной территории микрорайона).

В последние десятилетия наблюдается нарушение нормативного баланса застройки и лесопарковых зон городов. Можно отследить тенденцию увеличения и преобладания такого вида поверхности, как кровля и асфальтобетонные покрытия над газонами, что, в свою очередь, не может не отражаться на расходах дождевых сточных вод, поступающих на очистные сооружения в условиях урбанизированных территорий.

Основная расчетная формула (2) [1] и (20) [3] для определения расходов дождевых вод в коллекторах дождевой канадизации, л/с:
The article focuses on surface type ratio in towns and cities and its effect on rainwater expenditures and load on sewer networks. Calculations are provided for different surface coefficients (based on the Belski sewer outlet in Samara). It has been discovered that the more the value of the surface coefficient zmid is, the more expenditures are. The sewer network mentioned above cannot cope with rainwater load. However, bigger pipe diameter or parallel pipe laying is not always possible and/or reasonable. Thus, planting of greenery ought to be considered as a subsidiary way to lift part of the load from the sewer network.

Key words: surface type, rainwater expenditures, surface coefficient, backup.

$$
Q_{r}=z_{\text {mid }} \cdot A^{1,2} \cdot F / t_{r}^{0,2 n-0.1},
$$

где $z_{\text {mid }}$ - среднее значение коэффициента, характеризующего вид поверхности стока (коэффициент покрова), определяется как средневзвешенная величина в зависимости от коэффициентов $z_{i}$ для разиичных видов поверхностей по табл. 11 и 12 [3].

Из расчетной формулы (1) видна прямая зависимость расхода стока от вида поверхности: чем больше коэффициент покрова $z_{\text {mid’ }}$ тем больше расход, образующийся на единице площади данного типа территории.

В 80-х годах прошлого столетия на территории г. Самары значение коэффициента покрова достигало $z_{\text {mid }}=0.159$ (период утверждения генеральной схемы ливневой канализации, выполненной в 1983 г. институтом «Гипрокоммундортранс»). На данный момент это значение коэффициента покрова не соответствует действительности. 
Рассмотрим варианты возникающих расходов при изменении коэффициента покрова $z_{\text {mid }}$. Выполним поверочный расчет для четырех вариантов с раздичными комбинациями коэффициентов на примере выпуска «Бельского» Самарского склона г.о. Самара:

$$
\begin{aligned}
& 1 \text { - при } z_{\text {mid }}=0,18 \text { (табл. 1); } \\
& 2 \text { - при } z_{\text {mid }}=0,20 \text { (табл. 2); } \\
& 3 \text { - при } z_{\text {mid }}=0,25 \text { (табл. 3); } \\
& 4 \text { - при } z_{\text {mid }}=0,28 \text { (табл. 4). }
\end{aligned}
$$

Для участков, работающих с подпором, определим диаметры дополнительно параллельно прокладываемых трубопроводов (табл. 5-8).

При сравнении вариантов можно сделать вывод, что чем больше коэффициент покрова $z_{\text {mid }}$ тем больше расчетный расход. Имеющаяся сеть не будет справляться с поступающим кодичеством поверхностных сточных вод, и на участках сети, где ранее создавался подпор, высота издива увеличивается в нескодько раз. Все это приводит к быстрому затоплению улиц города.

По приведенным в табл. 5-8 данным мы видим, что прокладка параллельного трубопровода с уже имеющимся не всегда возможна из-за больших размеров первого или необходимости прокладки двух доподнительных трубопроводов. Следует рассматривать другие способы повышения работоспособности сложившейся системы дождевой канализации.
В свою очередь, коэффициент покрова $z_{i}$ напрямую зависит от долевого соотношения видов поверхности занимаемой территории.

Рассмотрим долевое соотношение видов поверхности при средних коэффициентах покрова $z_{\text {mid } 1}=0,159, z_{\text {mid } 2}=0,18, z_{\text {mid } 3}=0,20, z_{\text {mid4 }}=0,25, z_{\text {mids }}=0,28$. Определим коэффициент покрова по формуле

$$
z_{\text {mid }}=z_{1} \cdot a_{1}+z_{2} \cdot a_{2} \text {. }
$$

При этом можно найти $\mathrm{a}_{1}$ и $\mathrm{a}_{2}$, приняв $a_{2}=1-a_{1}$.

Тогда формула (2) будет выгдядеть следующим образом:

$$
z_{\text {mid }}=z_{1} \cdot a_{1}+z_{2} \cdot\left(1-a_{1}\right)
$$

где $z_{i}$ - коэффициент покрова для раздичных видов поверхностей, принимаем по табл. 11 [2] $z_{1}=0.28$ (вид поверхности стока - кровди и асфальтобетонные покрытия (водонепроницаемые поверхности), $z_{2}=0.038$ (вид поверхности стока - газоны).

Тогда формула (4) приобретает следующий вид для каждого варианта среднего значения коэф-

\begin{tabular}{|c|c|c|c|c|c|c|c|c|}
\hline $\begin{array}{c}\text { № } \\
\text { участка } \\
\text { сети }\end{array}$ & $\begin{array}{c}\text { Диаметр } \\
\text { трубы d, м }\end{array}$ & $\begin{array}{c}\text { Диина } \\
\text { участка } \\
1, \text { м }\end{array}$ & $\begin{array}{c}\text { Уклон } \\
\text { лотка } \\
\text { трубы і }\end{array}$ & $\begin{array}{c}\text { Падение } \\
\text { уклона } \\
\text { лотка } \\
\text { трубы і·I, } \\
\text { м }\end{array}$ & $\begin{array}{c}\text { Расчетная } \\
\text { скорость } \\
\text { течения } \\
\text { vр, м/с }\end{array}$ & $\begin{array}{c}\text { Факти- } \\
\text { ческая } \\
\text { скорость } \\
\text { течения } \\
\text { vф, м/с }\end{array}$ & $\begin{array}{c}\text { Пропуск- } \\
\text { ная спо- } \\
\text { собность } \\
\text { трубы при } \\
\text { h/d=1, А/с }\end{array}$ & Подпор, м \\
\hline 1 & 2 & 3 & 4 & 5 & 6 & 7 & 8 & 9 \\
\hline $1-2$ & 800 & 150 & 0,0432 & 6,48 & 5,26 & 0,41 & 2646 & 0,023 \\
\hline $2-3$ & 800 & 200 & 0,0492 & 9,84 & 5,36 & 0,71 & 2692 & 0,067 \\
\hline $3-4$ & 800 & 110 & 0,0035 & 0,38 & 1,5 & 0,71 & 754,6 & 0,067 \\
\hline $4-5$ & 800 & 160 & 0,0275 & 4,4 & 4,09 & 1,02 & 2057 & 0,138 \\
\hline $5-6$ & 800 & 90 & 0,043 & 3,87 & 5,11 & 1,91 & 2573 & 0,486 \\
\hline $6-7$ & 800 & 100 & 0,0431 & 4,31 & 5,11 & 2,83 & 2102 & 1,064 \\
\hline $7-8$ & 800 & 115 & 0,054 & 6,21 & 5,85 & 3,94 & 2941 & 2,062 \\
\hline $8-9$ & 800 & 300 & 0,057 & 17,11 & 6,1 & 7,34 & 3064 & 7,144 \\
\hline $9-10$ & 800 & 80 & 0,0653 & 5,22 & 6,31 & 7,96 & 3170 & 8,409 \\
\hline $10-11$ & 800 & 175 & 0,0339 & 5,94 & 4,14 & 12,52 & 2083 & 20,795 \\
\hline $11-12$ & 800 & 150 & 0,0393 & 5,89 & 4,83 & 12,52 & 2451 & 20,795 \\
\hline
\end{tabular}
фициента покрова:

$$
\begin{aligned}
& 0,159=0,28 \cdot a_{1}+0,038 \cdot\left(1-a_{1}\right) ; \\
& 0,18=0,28 \cdot a_{1}+0,038 \cdot\left(1-a_{1}\right) ; \\
& 0,2=0,28 \cdot a_{1}+0,038 \cdot\left(1-a_{1}\right) ; \\
& 0,25=0,28 \cdot a_{1}+0,038 \cdot\left(1-a_{1}\right) ; \\
& 0,28=0,28 \cdot a_{1}+0,038 \cdot\left(1-a_{1}\right) .
\end{aligned}
$$

Таблица 1

Ведомость поверочного расчета магистрадьного коддектора дождевой сети (выпуск «Бельский») для $\mathrm{z}_{\text {mid }}=0.18$ 
Окончание табл. 1

\begin{tabular}{|c|c|c|c|c|c|c|c|c|}
\hline $\begin{array}{c}\text { № } \\
\text { участка } \\
\text { сети }\end{array}$ & $\begin{array}{c}\text { Диаметр } \\
\text { трубы d, м }\end{array}$ & $\begin{array}{c}\text { Длина } \\
\text { участка } \\
\text { l, м }\end{array}$ & $\begin{array}{l}\text { Укдон } \\
\text { дотка } \\
\text { трубы і }\end{array}$ & $\begin{array}{c}\text { Падение } \\
\text { уклона } \\
\text { лотка } \\
\text { трубы і·I, } \\
\text { м } \\
\end{array}$ & $\begin{array}{c}\text { Расчетная } \\
\text { скорость } \\
\text { течения } \\
\text { vp, м/с }\end{array}$ & $\begin{array}{c}\text { Факти- } \\
\text { ческая } \\
\text { скорость } \\
\text { течения } \\
\text { vф, м/с } \\
\end{array}$ & $\begin{array}{c}\text { Пропуск- } \\
\text { ная спо- } \\
\text { собность } \\
\text { трубы при } \\
\text { h/d=1, ג/c }\end{array}$ & Подпор, м \\
\hline 1 & 2 & 3 & 4 & 5 & 6 & 7 & 8 & 9 \\
\hline $12-13$ & 1200 & 215 & 0,0004 & 0,08 & 0,65 & 5,57 & 731,3 & 4,108 \\
\hline 13-14 & 1200 & 200 & 0,0003 & 0,06 & 0,59 & 5,57 & 696,5 & 4,108 \\
\hline 14-15 & 1200 & 130 & 0,0238 & 3,1 & 4,74 & 5,57 & 5361 & 4,108 \\
\hline $15-16$ & 1200 & 75 & 0,0607 & 4,55 & 9,26 & 5,57 & 16362 & 4,108 \\
\hline $16-17$ & 1500 & 120 & 0,0143 & 1,71 & 4,49 & 3,56 & 7941 & 1,682 \\
\hline $17-18$ & 1500 & 30 & 0,04 & 1,2 & 7,52 & 3,56 & 13282 & 1,682 \\
\hline 18-19 & 1500 & 65 & 0,0157 & 1,02 & 4,75 & 3,56 & 8401 & 1,682 \\
\hline $19-20$ & 1500 & 140 & 0,0174 & 2,44 & 5,01 & 3,56 & 8860 & 1,682 \\
\hline $20-21$ & 1500 & 100 & 0,0242 & 2,42 & 5,85 & 3,56 & 10331 & 1,682 \\
\hline $21-22$ & 1500 & 150 & 0,0098 & 1,47 & 4,02 & 3,56 & 6213 & 1,682 \\
\hline $22-23$ & 1500 & 100 & 0,0599 & 5,99 & 8,72 & 3,67 & 15418 & 1,787 \\
\hline $23-24$ & 1500 & 50 & 0,1776 & 8,88 & 15,84 & 3,77 & 27978 & 1,889 \\
\hline $24-25$ & 1500 & 50 & 0,0034 & 0,17 & 2,19 & 3,77 & 3872 & 1,889 \\
\hline
\end{tabular}

Таблица 2

Ведомость поверочного расчета магистрадьного колдектора дождевой сети (выпуск «Бельский») для $\mathrm{z}_{\text {mid }}=0.20$

\begin{tabular}{|c|c|c|c|c|c|c|c|c|}
\hline $\begin{array}{c}\text { № } \\
\text { участка } \\
\text { сети }\end{array}$ & $\begin{array}{c}\text { Диаметр } \\
\text { трубы } \\
\text { d, м }\end{array}$ & $\begin{array}{c}\text { Диина } \\
\text { участка } \\
1, \text { м }\end{array}$ & $\begin{array}{c}\text { Укдон } \\
\text { дотка } \\
\text { трубы і }\end{array}$ & $\begin{array}{c}\text { Падение } \\
\text { укдона } \\
\text { лотка } \\
\text { трубы і·I, } \\
\text { м }\end{array}$ & $\begin{array}{c}\text { Расчетная } \\
\text { скорость } \\
\text { течения } \\
\text { vp, м/c }\end{array}$ & $\begin{array}{c}\text { Факти- } \\
\text { ческая } \\
\text { скорость } \\
\text { течения } \\
\text { vф, м/с }\end{array}$ & \begin{tabular}{|c|} 
Пропуск- \\
ная способ- \\
ность трубы \\
при h/d=1, \\
ג/c \\
\end{tabular} & $\begin{array}{c}\text { Подпор, } \\
\text { м }\end{array}$ \\
\hline 1 & 2 & 3 & 4 & 5 & 6 & 7 & 8 & 9 \\
\hline $1-2$ & 800 & 150 & 0,0432 & 6,48 & 5,26 & 0,46 & 2646 & 0,028 \\
\hline $2-3$ & 800 & 200 & 0,0492 & 9,84 & 5,36 & 0,79 & 2692 & 0,083 \\
\hline $3-4$ & 800 & 110 & 0,0035 & 0,38 & 1,5 & 0,56 & 754,6 & 0,042 \\
\hline $4-5$ & 800 & 160 & 0,0275 & 4,4 & 4,09 & 1,13 & 2057 & 0,170 \\
\hline $5-6$ & 800 & 90 & 0,043 & 3,87 & 5,11 & 2,13 & 2573 & 0,600 \\
\hline $6-7$ & 800 & 100 & 0,0431 & 4,31 & 5,11 & 3,15 & 2102 & 1,313 \\
\hline $7-8$ & 800 & 115 & 0,054 & 6,21 & 5,85 & 4,38 & 2941 & 2,546 \\
\hline 8-9 & 800 & 300 & 0,057 & 17,11 & 6,1 & 8,16 & 3064 & 8,819 \\
\hline $9-10$ & 800 & 80 & 0,0653 & 5,22 & 6,31 & 8,85 & 3170 & 10,382 \\
\hline $10-11$ & 800 & 175 & 0,0339 & 5,94 & 4,14 & 13,91 & 2083 & 25,672 \\
\hline $11-12$ & 800 & 150 & 0,0393 & 5,89 & 4,83 & 13,91 & 2451 & 25,672 \\
\hline $12-13$ & 1200 & 215 & 0,0004 & 0,08 & 0,65 & 6,18 & 731,3 & 5,071 \\
\hline $13-14$ & 1200 & 200 & 0,0003 & 0,06 & 0,59 & 6,18 & 696,5 & 5,071 \\
\hline $14-15$ & 1200 & 130 & 0,0238 & 3,1 & 4,74 & 6,18 & 5361 & 5,071 \\
\hline $15-16$ & 1200 & 75 & 0,0607 & 4,55 & 9,26 & 6,18 & 16362 & 5,071 \\
\hline $16-17$ & 1500 & 120 & 0,0143 & 1,71 & 4,49 & 3,96 & 7941 & 2,077 \\
\hline $17-18$ & 1500 & 30 & 0,04 & 1,2 & 7,52 & 3,96 & 13282 & 2,077 \\
\hline 18-19 & 1500 & 65 & 0,0157 & 1,02 & 4,75 & 3,96 & 8401 & 2,077 \\
\hline $19-20$ & 1500 & 140 & 0,0174 & 2,44 & 5,01 & 3,96 & 8860 & 2,077 \\
\hline
\end{tabular}


Окончание табл. 2

\begin{tabular}{|c|c|c|c|c|c|c|c|c|}
\hline $\begin{array}{c}\text { № } \\
\text { участка } \\
\text { сети }\end{array}$ & $\begin{array}{c}\text { Диаметр } \\
\text { трубы } \\
\text { d, м }\end{array}$ & $\begin{array}{c}\text { Длина } \\
\text { участка } \\
1, \text { м }\end{array}$ & $\begin{array}{c}\text { Уклон } \\
\text { лотка } \\
\text { трубы і }\end{array}$ & $\begin{array}{c}\text { Падение } \\
\text { укдона } \\
\text { лотка } \\
\text { трубы i·I, } \\
\text { м } \\
\end{array}$ & $\begin{array}{c}\text { Расчетная } \\
\text { скорость } \\
\text { течения } \\
\text { vp, м/с }\end{array}$ & $\begin{array}{c}\text { Факти- } \\
\text { ческая } \\
\text { скорость } \\
\text { течения } \\
\text { vф, м/с }\end{array}$ & $\begin{array}{c}\text { Пропуск- } \\
\text { ная способ- } \\
\text { ность трубы } \\
\text { при h/d=1, } \\
\text { ภ/c }\end{array}$ & $\begin{array}{c}\text { Подпор, } \\
\text { м }\end{array}$ \\
\hline 1 & 2 & 3 & 4 & 5 & 6 & 7 & 8 & 9 \\
\hline $20-21$ & 1500 & 100 & 0,0242 & 2,42 & 5,85 & 3,96 & 10331 & 2,077 \\
\hline $21-22$ & 1500 & 150 & 0,0098 & 1,47 & 4,02 & 3,96 & 6213 & 2,077 \\
\hline $22-23$ & 1500 & 100 & 0,0599 & 5,99 & 8,72 & 4,08 & 15418 & 2,206 \\
\hline $23-24$ & 1500 & 50 & 0,1776 & 8,88 & 15,84 & 4,19 & 27978 & 2,332 \\
\hline $24-25$ & 1500 & 50 & 0,0034 & 0,17 & 2,19 & 4,19 & 3872 & 2,332 \\
\hline
\end{tabular}

Таблица 3

Ведомость поверочного расчета магистрадьного колдектора дождевой сети (выпуск «Бельский») для $\mathrm{z}_{\mathrm{mid}}=\mathbf{0 . 2 5}$

\begin{tabular}{|c|c|c|c|c|c|c|c|c|c|c|}
\hline \multirow{2}{*}{$\begin{array}{c}\text { № } \\
\text { участка } \\
\text { сети }\end{array}$} & \multirow{2}{*}{$\begin{array}{c}\text { Диаметр } \\
\text { трубы } \\
\text { d, м }\end{array}$} & \multirow{2}{*}{$\begin{array}{c}\text { Длина } \\
\text { участка } \\
1, \mathrm{м}\end{array}$} & \multirow{2}{*}{$\begin{array}{c}\text { Уклон } \\
\text { лотка } \\
\text { трубы } \\
\text { i }\end{array}$} & \multirow{2}{*}{$\begin{array}{c}\text { Паде- } \\
\text { ние } \\
\text { уклона } \\
\text { дотка } \\
\text { трубы } \\
\text { i·I, м }\end{array}$} & \multirow{2}{*}{$\begin{array}{c}\text { Расчетная } \\
\text { скорость } \\
\text { течения } \\
\text { vр, м/с }\end{array}$} & \multirow{2}{*}{$\begin{array}{c}\text { Факти- } \\
\text { ческая } \\
\text { скорость } \\
\text { течения } \\
\text { vф, м/с }\end{array}$} & \multirow{2}{*}{$\begin{array}{c}\text { Пропуск- } \\
\text { ная спо- } \\
\text { собность } \\
\text { трубы } \\
\text { при } \\
\text { h/d=1, ג/c }\end{array}$} & \multirow[t]{2}{*}{$\begin{array}{c}\text { Подпор, } \\
\text { м }\end{array}$} & \multicolumn{2}{|c|}{$\begin{array}{c}\text { Отметки, м } \\
\text { поверхности } \\
\text { земли }\end{array}$} \\
\hline & & & & & & & & & в начале & в конце \\
\hline 1 & 2 & 3 & 4 & 5 & 6 & 7 & 8 & 9 & 10 & 11 \\
\hline $1-2$ & 800 & 150 & 0,0432 & 6,48 & 5,26 & 0,57 & 2646 & 0,044 & 133,4 & 127,2 \\
\hline $2-3$ & 800 & 200 & 0,0492 & 9,84 & 5,36 & 0,99 & 2692 & 0,130 & 127,2 & 119,6 \\
\hline $3-4$ & 800 & 110 & 0,0035 & 0,38 & 1,5 & 0,99 & 754,6 & 0,130 & 119,6 & 117,4 \\
\hline $4-5$ & 800 & 160 & 0,0275 & 4,4 & 4,09 & 1,42 & 2057 & 0,266 & 117,4 & 113,4 \\
\hline $5-6$ & 800 & 90 & 0,043 & 3,87 & 5,11 & 2,66 & 2573 & 0,938 & 113,4 & 110,3 \\
\hline $6-7$ & 800 & 100 & 0,0431 & 4,31 & 5,11 & 3,93 & 2102 & 2,052 & 110,3 & 105,5 \\
\hline $7-8$ & 800 & 115 & 0,054 & 6,21 & 5,85 & 5,48 & 2941 & 3,978 & 105,5 & 98,49 \\
\hline $8-9$ & 800 & 300 & 0,057 & 17,11 & 6,1 & 10,19 & 3064 & 13,780 & 98,49 & 82,02 \\
\hline $9-10$ & 800 & 80 & 0,0653 & 5,22 & 6,31 & 11,06 & 3170 & 16,222 & 82,02 & 81,1 \\
\hline $10-11$ & 800 & 175 & 0,0339 & 5,94 & 4,14 & 17,39 & 2083 & 40,113 & 81,1 & 72,76 \\
\hline $11-12$ & 800 & 150 & 0,0393 & 5,89 & 4,83 & 17,39 & 2451 & 40,113 & 72,76 & 65,9 \\
\hline $12-13$ & 1200 & 215 & 0,0004 & 0,08 & 0,65 & 7,73 & 731,3 & 7,924 & 65,9 & 66,29 \\
\hline $13-14$ & 1200 & 200 & 0,0003 & 0,06 & 0,59 & 7,73 & 696,5 & 7,924 & 66,29 & 67,76 \\
\hline 14-15 & 1200 & 130 & 0,0238 & 3,1 & 4,74 & 7,73 & 5361 & 7,924 & 67,76 & 64,63 \\
\hline $15-16$ & 1200 & 75 & 0,0607 & 4,55 & 9,26 & 7,73 & 16362 & 7,924 & 64,63 & 64,83 \\
\hline $16-17$ & 1500 & 120 & 0,0143 & 1,71 & 4,49 & 4,95 & 7941 & 3,246 & 64,83 & 59,19 \\
\hline $17-18$ & 1500 & 30 & 0,04 & 1,2 & 7,52 & 4,95 & 13282 & 3,246 & 59,19 & 58,37 \\
\hline $18-19$ & 1500 & 65 & 0,0157 & 1,02 & 4,75 & 4,95 & 8401 & 3,246 & 58,37 & 56,55 \\
\hline $19-20$ & 1500 & 140 & 0,0174 & 2,44 & 5,01 & 4,95 & 8860 & 3,246 & 56,55 & 52,64 \\
\hline $20-21$ & 1500 & 100 & 0,0242 & 2,42 & 5,85 & 4,95 & 10331 & 3,246 & 52,64 & 50,54 \\
\hline $21-22$ & 1500 & 150 & 0,0098 & 1,47 & 4,02 & 4,95 & 6213 & 3,246 & 50,54 & 48,65 \\
\hline $22-23$ & 1500 & 100 & 0,0599 & 5,99 & 8,72 & 5,10 & 15418 & 3,447 & 48,65 & 43,93 \\
\hline $23-24$ & 1500 & 50 & 0,1776 & 8,88 & 15,84 & 5,24 & 27978 & 3,644 & 43,93 & 36,48 \\
\hline $24-25$ & 1500 & 50 & 0,0034 & 0,17 & 2,19 & 5,24 & 3872 & 3,644 & 36,48 & 31,83 \\
\hline
\end{tabular}


Таблица 4

Ведомость поверочного расчета магистрадьного колдектора дождевой сети (выпуск «Бельский») для $\mathrm{z}_{\mathrm{mid}}=0.28$

\begin{tabular}{|c|c|c|c|c|c|c|c|c|c|}
\hline $\begin{array}{c}\text { № } \\
\text { участка } \\
\text { сети }\end{array}$ & $\begin{array}{c}\text { Диаметр } \\
\text { трубы d, м }\end{array}$ & $\begin{array}{c}\text { Длина } \\
\text { участка } \\
1, \text { м }\end{array}$ & $\begin{array}{c}\text { Уклон } \\
\text { лотка } \\
\text { трубы і }\end{array}$ & $\begin{array}{c}\text { Падение } \\
\text { уклона } \\
\text { лотка } \\
\text { трубы і·I, } \\
\text { м }\end{array}$ & $\begin{array}{c}\text { Расчетная } \\
\text { скорость } \\
\text { течения } \\
\text { vp, м/с }\end{array}$ & $\begin{array}{c}\text { Факти- } \\
\text { ческая } \\
\text { скорость } \\
\text { течения } \\
\text { vф, м/с }\end{array}$ & $\begin{array}{c}\text { Пропуск- } \\
\text { ная спо- } \\
\text { собность } \\
\text { трубы при } \\
\text { h/d=1, } / \mathrm{c}\end{array}$ & $\begin{array}{c}\text { Подпор, } \\
\text { м }\end{array}$ & $\begin{array}{c}\text { Отметки } \\
\text { поверхно- } \\
\text { сти земли } \\
\text { в начале, } \\
\text { м }\end{array}$ \\
\hline 1 & 2 & 3 & 4 & 5 & 6 & 7 & 8 & 9 & 10 \\
\hline $1-2$ & 800 & 150 & 0,0432 & 6,48 & 5,26 & 0,64 & 2646 & 0,055 & 133,4 \\
\hline $2-3$ & 800 & 200 & 0,0492 & 9,84 & 5,36 & 1,11 & 2692 & 0,163 & 127,2 \\
\hline $3-4$ & 800 & 110 & 0,0035 & 0,38 & 1,5 & 1,11 & 754,6 & 0,163 & 119,6 \\
\hline $4-5$ & 800 & 160 & 0,0275 & 4,4 & 4,09 & 1,59 & 2057 & 0,334 & 117,4 \\
\hline $5-6$ & 800 & 90 & 0,043 & 3,87 & 5,11 & 2,98 & 2573 & 1,176 & 113,4 \\
\hline $6-7$ & 800 & 100 & 0,0431 & 4,31 & 5,11 & 4,41 & 2102 & 2,574 & 110,3 \\
\hline $7-8$ & 800 & 115 & 0,054 & 6,21 & 5,85 & 6,13 & 2941 & 4,990 & 105,5 \\
\hline $8-9$ & 800 & 300 & 0,057 & 17,11 & 6,1 & 11,42 & 3064 & 17,286 & 98,49 \\
\hline $9-10$ & 800 & 80 & 0,0653 & 5,22 & 6,31 & 12,39 & 3170 & 20,349 & 82,02 \\
\hline $10-11$ & 800 & 175 & 0,0339 & 5,94 & 4,14 & 19,48 & 2083 & 50,318 & 81,1 \\
\hline $11-12$ & 800 & 150 & 0,0393 & 5,89 & 4,83 & 19,48 & 2451 & 50,318 & 72,76 \\
\hline $12-13$ & 1200 & 215 & 0,0004 & 0,08 & 0,65 & 4,26 & 731,3 & 2,402 & 65,9 \\
\hline $13-14$ & 1200 & 200 & 0,0003 & 0,06 & 0,59 & 4,26 & 696,5 & 2,402 & 66,29 \\
\hline $14-15$ & 1200 & 130 & 0,0238 & 3,1 & 4,74 & 4,26 & 5361 & 2,402 & 67,76 \\
\hline $15-16$ & 1200 & 75 & 0,0607 & 4,55 & 9,26 & 6,00 & 16362 & 4,770 & 64,63 \\
\hline $16-17$ & 1500 & 120 & 0,0143 & 1,71 & 4,49 & 3,84 & 7941 & 1,954 & 64,83 \\
\hline $17-18$ & 1500 & 30 & 0,04 & 1,2 & 7,52 & 4,20 & 13282 & 2,342 & 59,19 \\
\hline $18-19$ & 1500 & 65 & 0,0157 & 1,02 & 4,75 & 4,20 & 8401 & 2,342 & 58,37 \\
\hline $19-20$ & 1500 & 140 & 0,0174 & 2,44 & 5,01 & 4,20 & 8860 & 2,342 & 56,55 \\
\hline $20-21$ & 1500 & 100 & 0,0242 & 2,42 & 5,85 & 4,20 & 10331 & 2,342 & 52,64 \\
\hline $21-22$ & 1500 & 150 & 0,0098 & 1,47 & 4,02 & 4,20 & 6213 & 2,342 & 50,54 \\
\hline $22-23$ & 1500 & 100 & 0,0599 & 5,99 & 8,72 & 5,71 & 15418 & 4,324 & 48,65 \\
\hline $23-24$ & 1500 & 50 & 0,1776 & 8,88 & 15,84 & 5,87 & 27978 & 4,571 & 43,93 \\
\hline $24-25$ & 1500 & 50 & 0,0034 & 0,17 & 2,19 & 5,87 & 3872 & 4,571 & 36,48 \\
\hline
\end{tabular}

Таблица 5

Определение диаметра дополнительных трубопроводов на участках, работающих с переполнением сети для $\mathrm{z}_{\text {mid }}=0,18$

\begin{tabular}{|c|c|c|c|c|c|c|c|c|c|c|}
\hline $\begin{array}{c}\text { № } \\
\text { участ- } \\
\text { ка }\end{array}$ & $\mathrm{d}_{\phi^{\prime}}, \mathrm{MM}$ & $\mathrm{i}_{\phi}$ & $\mathrm{q}_{\text {пр.сп, }}, \lambda / \mathrm{c}$ & $\mathrm{q}_{\mathrm{p}^{\prime}}, \Lambda / \mathrm{c}$ & $\mathrm{q}_{\text {щ }}=\mathrm{q}_{\mathrm{p}}-\mathrm{q}_{\text {пр.сп丿 }}, \lambda / \mathrm{c}$ & $\mathrm{d}_{\text {доп' }}, \mathrm{MM}$ & $\mathrm{q}_{\text {таб.доп' }}, \lambda / \mathrm{c}$ & $\mathrm{v}_{\text {доп' }}, \mathrm{M} / \mathrm{C}$ & $\begin{array}{c}\text { Подпор, } \\
\text { м }\end{array}$ & $\begin{array}{c}\text { Зало- } \\
\text { жение } \\
\text { лотка } \\
\text { трубы } \\
\text { в начале } \\
\text { участка, } \\
\text { м }\end{array}$ \\
\hline 1 & 2 & 3 & 4 & 5 & 6 & 7 & 8 & 9 & 10 & 11 \\
\hline $8-9$ & 800 & 0,057 & 3064 & 3687,68 & 623,68 & 500 & 847,12 & 4,31 & 1,29 & 2,51 \\
\hline $9-10$ & 800 & 0,0653 & 3170 & 4001,05 & 830,95 & 500 & 906,70 & 4,62 & 2,29 & 3,15 \\
\hline $10-11$ & 800 & 0,0339 & 2083 & 6291,68 & 4208,38 & 1000 & 4136,02 & 5,24 & 3,76 & 7,45 \\
\hline
\end{tabular}


Окончание табл. 5

\begin{tabular}{|c|c|c|c|c|c|c|c|c|c|c|}
\hline $\begin{array}{c}\text { № } \\
\text { участ- } \\
\text { ка }\end{array}$ & $\mathrm{d}_{\phi^{\prime}} \mathrm{MM}$ & $i_{\phi}$ & $\mathrm{q}_{\text {пр.сп, }}, \Lambda / \mathrm{c}$ & $\mathrm{q}_{\mathrm{p}^{\prime}} \mathrm{A} / \mathrm{c}$ & $\mathrm{q}_{\text {世 }}=\mathrm{q}_{\mathrm{p}}-\mathrm{q}_{\text {пр.сn' }}, \mathrm{L} / \mathrm{c}$ & $\mathrm{d}_{\text {AOII }}$ MM & $\mathrm{q}_{\text {таб.доп口' }} \Lambda / \mathrm{c}$ & $\mathrm{v}_{\text {доп' }}, \mathrm{M} / \mathrm{C}$ & $\begin{array}{c}\text { Подпор, } \\
\text { м }\end{array}$ & $\begin{array}{c}\text { Зало- } \\
\text { жение } \\
\text { лотка } \\
\text { трубы } \\
\text { в начале } \\
\text { участка, } \\
\text { м }\end{array}$ \\
\hline 1 & 2 & 3 & 4 & 5 & 6 & 7 & 8 & 9 & 10 & 11 \\
\hline $11-12$ & 800 & 0,0393 & 2451 & 6291,68 & 3840,68 & 1000 & 4461,09 & 5,68 & 3,13 & 4,05 \\
\hline $12-13$ & 1200 & 0,0004 & 731,3 & 6291,68 & 5560,38 & 2200 & 2484,86 & 0,88 & 0,28 & 3,08 \\
\hline $13-14$ & 1200 & 0,0003 & 696,5 & 6291,68 & 5595,18 & 2200 & 2151,95 & 0,76 & 0,29 & 3,55 \\
\hline
\end{tabular}

Таблица 6

Определение диаметра доподнительных трубопроводов на участках, работающих с переполнением сети для $\mathrm{z}_{\text {mid }}=0,20$

\begin{tabular}{|c|c|c|c|c|c|c|c|c|c|c|}
\hline $\begin{array}{c}\text { № } \\
\text { участ- } \\
\text { ка }\end{array}$ & $\mathrm{d}_{\phi^{\prime}} \mathrm{MM}$ & $\mathrm{i}_{\phi}$ & $\begin{array}{c}\mathrm{q} \Pi_{\mathrm{p} . \mathrm{cr}{ }^{\prime}} \\
\Lambda / \mathrm{C}\end{array}$ & $\mathrm{q}_{p^{\prime}}, \Lambda / c$ & $\mathrm{q}_{\text {щ }}=\mathrm{q}_{\mathrm{p}}-\mathrm{q}_{\text {пр.спи' }}, \Lambda / \mathrm{c}$ & $\mathrm{d}_{\text {доा' }}, \mathrm{MM}$ & $\mathrm{q}_{\text {таб.доп' }}, \mathrm{h} / \mathrm{c}$ & $\mathrm{v}_{\text {доп' }}, \mathrm{M} / \mathrm{C}$ & $\begin{array}{c}\text { Подпор, } \\
\text { м }\end{array}$ & $\begin{array}{c}\text { Зало- } \\
\text { жение } \\
\text { дотка } \\
\text { трубы } \\
\text { в начале } \\
\text { участка, } \\
\text { м }\end{array}$ \\
\hline 1 & 2 & 3 & 4 & 5 & 6 & 7 & 8 & 9 & 10 & 11 \\
\hline $8-9$ & 800 & 0,057 & 3064 & 4097,42 & 1033,42 & 600 & 1377,29 & 4,87 & 1,81 & 2,51 \\
\hline $9-10$ & 800 & 0,0653 & 3170 & 4445,61 & 1275,51 & 600 & 1474,16 & 5,21 & 2,75 & 3,15 \\
\hline $10-11$ & 800 & 0,0339 & 2083 & 6990,76 & 4907,46 & 1100 & 5340,63 & 5,62 & 3,54 & 7,45 \\
\hline $11-12$ & 800 & 0,0393 & 2451 & 6990,76 & 4539,76 & 1100 & 5750,28 & 6,05 & 3,03 & 4,05 \\
\hline $12-13$ & 1200 & 0,0004 & 731,3 & 6990,76 & 6259,46 & 1900 & 3822,37 & 1,06 & 0,65 & 3,08 \\
\hline $13-14$ & 1200 & 0,0003 & 696,5 & 6990,76 & 6294,26 & 1900 & 3310,27 & 0,92 & 0,66 & 3,55 \\
\hline $14-15$ & 1200 & 0,0238 & 5361 & 6990,76 & 1629,36 & 700 & 2067,90 & 4,22 & 2,44 & 5,08 \\
\hline $15-16$ & 1200 & 0,0607 & 16362 & 6990,76 & $-9370,84$ & 1500 & 25117,08 & 11,16 & 3,72 & 5,05 \\
\hline
\end{tabular}

Таблица 7

Определение диаметра доподнитедьных трубопроводов на участках, работающих с переподнением сети для $\mathrm{z}_{\mathrm{mid}}=0,25$

\begin{tabular}{|c|c|c|c|c|c|c|c|c|c|c|}
\hline $\begin{array}{c}\text { № } \\
\text { участ- } \\
\text { ка }\end{array}$ & $\mathrm{d}_{\phi^{\prime}} \mathrm{MM}$ & $\mathrm{i}_{\phi}$ & $\mathrm{q}_{\text {пр.сп' }}, \lambda / \mathrm{c}$ & $\mathrm{q}_{\mathrm{p}^{\prime}}, \mathrm{A} / \mathrm{c}$ & $\mathrm{q}_{щ}=\mathrm{q}_{\mathrm{p}}-\mathrm{q} \Pi_{\mathrm{p} . \mathrm{c} \Pi^{\prime}}, \Lambda / \mathrm{c}$ & $\mathrm{d}_{\text {доп' }}, \mathrm{MM}$ & $\mathrm{q}_{\text {таб.доп' }}, \lambda / \mathrm{c}$ & $\mathrm{V}_{\text {доп' }}, \mathrm{M} / \mathrm{C}$ & $\begin{array}{c}\text { Подпор, } \\
\text { м }\end{array}$ & $\begin{array}{c}\text { Зало- } \\
\text { жение } \\
\text { дотка } \\
\text { трубы } \\
\text { в начале } \\
\text { участка, } \\
\text { м }\end{array}$ \\
\hline 1 & 2 & 3 & 4 & 5 & 6 & 7 & 8 & 9 & 10 & 11 \\
\hline $7-8$ & 800 & 0,054 & 2941 & 2751,72 & $-189,28$ & 300 & 211,18 & 2,99 & 0,97 & 3,28 \\
\hline $8-9$ & 800 & 0,057 & 3064 & 5121,78 & 2057,78 & 800 & 2964,81 & 5,9 & 2,25 & 2,51 \\
\hline $9-10$ & 800 & 0,0653 & 3170 & 5557,02 & 2386,92 & 900 & 4343,17 & 6,83 & 1,84 & 3,15 \\
\hline $10-11$ & 800 & 0,0339 & 2083 & 8738,45 & 6655,15 & 1400 & 10149,93 & 6,59 & 2,48 & 7,45 \\
\hline $11-12$ & 800 & 0,0393 & 2451 & 8738,45 & 6287,45 & 1400 & 10928,27 & 7,1 & 2,21 & 4,05 \\
\hline
\end{tabular}


Окончание табл. 7

\begin{tabular}{|c|c|c|c|c|c|c|c|c|c|c|}
\hline $\begin{array}{c}\text { № } \\
\text { участ- } \\
\text { ка }\end{array}$ & $\mathrm{d}_{\phi^{\prime}} \mathrm{MM}$ & $\mathrm{i}_{\phi}$ & $\mathrm{q}_{\text {пр.сr' }}, \mathrm{h} / \mathrm{c}$ & $\mathrm{q}_{\mathrm{p}^{\prime}} \mathrm{n} / \mathrm{c}$ & $\mathrm{q}_{\text {щl }}=\mathrm{q}_{\mathrm{p}}-\mathrm{q} \Pi_{\mathrm{p} . \mathrm{cr} \mathbf{\prime}^{\prime}}, \lambda / \mathrm{c}$ & $\mathrm{d}_{\text {AOI' }}, \mathrm{MM}$ & $\mathrm{q}_{\text {таб.догт⿱ }}, \mathrm{x} / \mathrm{c}$ & $\mathrm{V}_{\text {AоO }}, \mathrm{M} / \mathrm{C}$ & $\begin{array}{c}\text { Подпор, } \\
\text { м }\end{array}$ & $\begin{array}{c}\text { Зало- } \\
\text { жение } \\
\text { дотка } \\
\text { трубы } \\
\text { в начале } \\
\text { участка, } \\
\text { м }\end{array}$ \\
\hline 1 & 2 & 3 & 4 & 5 & 6 & 7 & 8 & 9 & 10 & 11 \\
\hline $12-13$ & 1200 & 0,0004 & 731,3 & 8738,45 & 8007,15 & 1900 & 3822,37 & 1,06 & 1,06 & 3,08 \\
\hline $13-14$ & 1200 & 0,0003 & 696,5 & 8738,45 & 8041,95 & 1900 & 3310,27 & 0,92 & 1,07 & 3,55 \\
\hline $14-15$ & 1200 & 0,0238 & 5361 & 8738,45 & 3377,05 & 1000 & 3471,63 & 4,42 & 2,42 & 5,08 \\
\hline $15-16$ & 1200 & 0,0607 & 16362 & 8738,45 & $-7623,15$ & 1300 & 11150,05 & 8,40 & 4,36 & 5,05 \\
\hline
\end{tabular}

Таблица 8

Определение диаметра дополнительных трубопроводов на участках, работающих с переполнением сети для $\mathrm{z}_{\text {mid }}=0,28$

\begin{tabular}{|c|c|c|c|c|c|c|c|c|c|c|}
\hline $\begin{array}{c}\text { № } \\
\text { участ- } \\
\text { ка }\end{array}$ & $\mathrm{d}_{\phi^{\prime}} \mathrm{MM}$ & $\mathrm{i}_{\phi}$ & $\mathrm{q}_{\text {пр.сп, }}, \lambda / \mathrm{c}$ & $\mathrm{q}_{p^{\prime}}, \Lambda / \mathrm{c}$ & $\mathrm{q}_{\amalg}=\mathrm{q}_{\mathrm{p}}-\mathrm{q}_{\text {пр.сп}}, \Lambda / \mathrm{c}$ & $\mathrm{d}_{\text {доп' }}, \mathrm{MM}$ & $\mathrm{q}_{\text {таб.доп' }}, \lambda / \mathrm{c}$ & $\mathrm{V}_{\text {доп, }}, \mathrm{M} / \mathrm{C}$ & $\begin{array}{c}\text { Подпор, } \\
\text { м }\end{array}$ & $\begin{array}{c}\text { Зало- } \\
\text { жение } \\
\text { лотка } \\
\text { трубы } \\
\text { в начале } \\
\text { участка, } \\
\text { м }\end{array}$ \\
\hline 1 & 2 & 3 & 4 & 5 & 6 & 7 & 8 & 9 & 10 & 11 \\
\hline $7-8$ & 800 & 0,054 & 2941 & 3081,93 & 140,93 & 300 & 211,18 & 2,99 & 0,54 & 3,28 \\
\hline $8-9$ & 800 & 0,057 & 3064 & 5736,39 & 2672,39 & 800 & 2964,81 & 5,9 & 3,79 & 2,51 \\
\hline $9-10$ & 800 & 0,0653 & 3170 & 6223,86 & 3053,76 & 900 & 4343,17 & 6,83 & 3,02 & 3,15 \\
\hline $10-11$ & 800 & 0,0339 & 2083 & 9787,07 & 7703,77 & 1300 & 8332,63 & 6,28 & 4,45 & 7,45 \\
\hline $11-12$ & 800 & 0,0393 & 2451 & 9787,07 & 7336,07 & 1300 & 8971,78 & 6,76 & 4,03 & 4,05 \\
\hline $22-23$ & 1500 & 0,0599 & 15418 & 10086,4 & $-5331,55$ & 1300 & 11076,33 & 8,34 & 2,13 & 3,88 \\
\hline
\end{tabular}

Решив эти уравнения, получим следующие данные по вариантам:

$$
\begin{array}{ll}
\text { при } z_{\text {mid }}=0,159 & a_{1}=0,5, a_{2}=0,5 ; \\
\text { при } z_{\text {mid }}=0,18 & a_{1}=0,59, a_{2}=0,41 ; \\
\text { при } z_{\text {mid }}=0,2 & a_{1}=0,67, a_{2}=0,33 ; \\
\text { при } z_{\text {mid }}=0,25 & a_{1}=0,88, a_{2}=0,12 ; \\
\text { при } z_{\text {mid }}=0,28 & a_{1}=1, a_{2}=0 .
\end{array}
$$

Полученные данные отображены на рис. 1.

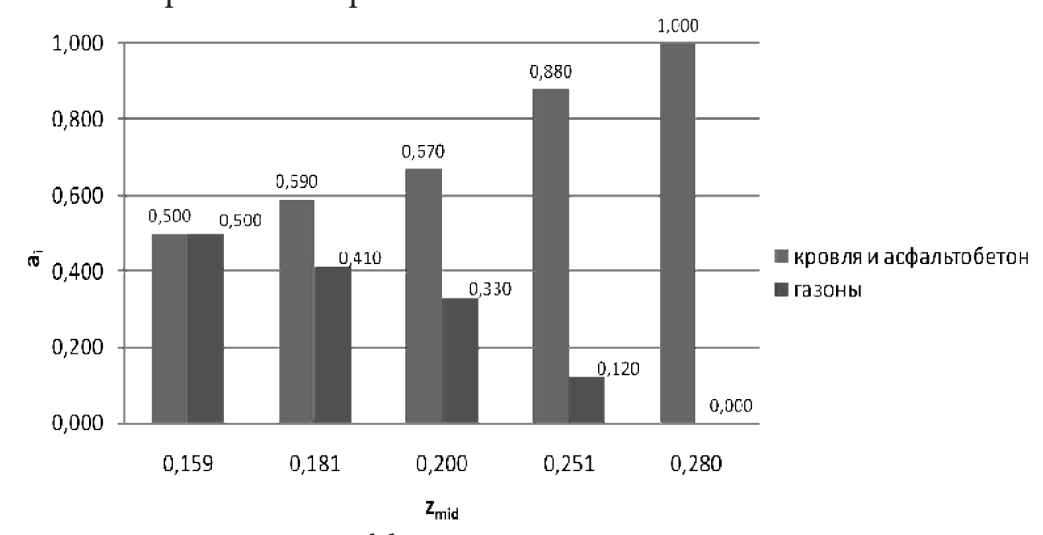

Рис. 1. Соотношение типов поверхностей при разных коэффициентах покрова 
Из рис. 1 видно, что при увеличении значения коэффициента покрова соотношение между двумя типами поверхностей изменяется в сторону увеличения доли кровли и асфальтобетонных покрытий, которая достигает своего пика при значение $\mathrm{z}_{\text {mid }}=0,28$ (значение $\mathrm{a}_{1}$ составляет 1 , а доля газонов в этом случае равна нулю).

Если объединить полученные данные из графика и поверочных расчетов, то можно будет сделать следующие выводы.

Изменение в соотношении типов поверхностей городов (в условиях непропорционального их развития в соответствии с действующими нормативами) повлечет за собой, в первую очередь, возрастающую нагрузку на существующие сети дождевой канализации. Как следствие - работа в напорном режиме (подпор), износ сетей, затопление улиц и магистралей города.

Достижение критического значения коэффициента покрова $\mathrm{z}_{\mathrm{mid}}=0.25$, при котором соотношение долей поверхностей водонепроницаемого типа и газонов достигнет своего нормативного предела, может привести к фактическому затоплению улиц города, также это повлечет за собой увеличение нагрузки на существующие сооружения поверхностного стока, и в этом случае нужно рассматривать возможность полной замены системы дождевой канализации дибо в корне изменить систему канализования дождевых стоков.
Возможно рассмотрение озеленения улиц как вспомогательного способа улучшения системы канализования. Увеличение доди газонов приведет к снижению величины $\mathrm{z}_{\text {mid }^{\prime}}$ что, в конечном счете, уменьшит расход дождевых вод с территории города.

\section{БИБЯИОГРАФИЧЕСКИЙ СПИСОК}

1. СНиП 2.04.03-85. Канализация. Наружные сети и сооружения [Текст]. - М.: ФГУП ЦПП, 2007. - 87 с.

2. СНиП 2.07.01-89. Градостроительство. Планировка и застройка городских и сельских поселений [Текст] / Госстрой СССР. - М.: ЦИТП Госстроя СССР, 1989. -56 c.

3. Рекомендации по расчету систем сбора, отведения и очистки поверхностного стока с седитебных территорий, площадок предприятий и определению условий выпуска его в водные объекты [Текст] / В.Н. Швецов, А.Н. Белевцев, Л.М. Верещагина и др. - М.: ФГУП «НИИ ВОДГЕО»; Подольск: Филиал ОАО «ЧПК», 2006. -56 c.

(C) Стрелков А.К., Гриднева М.А., Кондрина Е.Е., 2011 